\title{
THE KUHNIAN NOTION OF PARADIGM IN THE THIRD INTERNATIONAL RELATIONS DEBATE
}

\author{
Hristina Dobreva ${ }^{1}$ \\ Rakovski National Defence College, Sofia, Bulgaria
}

\begin{abstract}
The paper reviews some of the major IR scholars and how they view the applicability of Kuhn's notion of paradigm in the case of the third IR debate. The starting point is Laipd's idea of positivism versus post-positivism. I argue that pessimism and optimism are interrelated in the debate. Also, for the future, if the IR scientific community wants to contribute to real problem solution, it should not restrict to the narrow notion of Kuhn's paradigm. However, there should be some loose sense of a paradigm as a cumulation of lessons learned. The grand theorizing or bridge-building should be replaced by the idea of lots of "doors" or many mediators linking only certain issues in different approaches. If there is only one bridge, this will not adequately reflect the emerging stage of proliferation of pluralism in the field. The pragmatic tendency is towards eclecticism of the approaches. Elements are interrelated and the border between positivism and relativism is moving.
\end{abstract}

Keywords: Kuhn; paradigm; debates in International Relations.

\section{INTRODUCTION}

I approach this topic as a review of some of the major IR scholars and their contribution to the intellectual history of the discipline. I refrain from arguing whether this is the current debate. However, still it continues to be relevant at the moment. ${ }^{2}$ The issue, taken into consideration, is how they view the applicability of Kuhn's notion of paradigm in the case of the third IR debate. Although, as Goldmann mentions ${ }^{3}$, there is no clear agreement about the challenger of the mainstream in the debate, my paper takes Laipd's idea of positivism versus post-positivism as a starting point. The debate is generally seen as an opposition between the mainstream (neorealism and neoliberalism) with their rational choice methodology, and relativism or the proliferation of theory-liberating approaches, especially after the end of the Cold war. However, neorealism seems to have received more attacks than neoliberalism ${ }^{4}$. Disagreements in the field are further encouraged because IR, by nature involves political, and consequently power implications.

I argue that pessimism and optimism are interrelated in the debate. Also, for the future, if the IR scientific community wants to contribute to real problem solution, it should not restrict to the narrow notion of Kuhn's paradigm. However, there should be some loose sense of a paradigm as a cumulation of lessons learned, as mentioned by Dogan. This loose sense of paradigm prevents from the extreme version of relativism seen as a cacophony of voices. In Kuhnian language, the current IR

\footnotetext{
${ }^{1}$ Corresponding author: h.dobreva@rndc.bg.

${ }^{2}$ Some literature argues that there is a Fourth and even a Fifth Debate. Examples of literature arguing about the Fourth Debate include the following books: Robert Jackson, Georg Sorensen, Jorgen Moller-Introduction to International Relations, Theories and Approaches, Seventh edition, Oxford University Press, UK, 2019 and Tim Dunne, Milja Kurki, and Steve SmithInternational Relations Theories, Discipline and Diversity, Third edition, Oxford University Press, UK, 2013. Examples of literature arguing about a Fifth Debate include: Emilian Kavalski, "The Fifth Debate and the Emergence of Complex International Relations Theory: Notes on the Application of Complexity Theory to the Study of International Life", Pages 435454, Published online: 04 Sep 2007, Cambridge Review of International Affairs, Volume 20, 2007-Issue 3 and Gavin Stewart, "Science Bound? Transcending the Fourth 'Great Debate' in International Relations", Apr.3 2014, https://www.eir.info/2014/04/03/science-bound-transcending-the-fourth-great-debate-in-international-relations/.

${ }^{3}$ See ch.16 in Goodin and Klingemann, pp.401-427.

${ }^{4}$ It is interesting that realism or modifications of realism have participated in all of the debates. This makes me wonder whether realism is the challenged or the constant challenger.
} 
stage is a transition to maturity where maturity is related to the ideal post-paradigm stage with no debates.

The debate is further complicated by internal disagreements within the camps and by the emerging tendency, especially within the mainstream, to regard constuctivism as a mediator or the new middle ground in the debate. However, the whole idea about the construction of a bridge between positivism and post-positivism is questionable when it comes to problem solutions for concrete cases. Rather, this grand theorizing or bridge-building should be replaced by the idea of lots of "doors" or many mediators linking only certain issues in different approaches.

My paper is divided in two parts. The first starts with the differences between natural and social sciences to explain why a fixed notion of paradigm is not possible in social sciences. However, the first part focuses on Kuhn's two meanings of paradigm and on the current modifications offered by Dogan and Lichbach. The second part's task is to show how different IR scholars interpret the debate starting from, but without referring to a particular meaning of the Kuhn's paradigm. The interpretations are divided into optimistic and pessimistic in their view of the future of the debate. May be Kuhn is not so controversial, as some accuse him, because he incorporates positivism and relativism as complementing tendencies. His notion of paradigm may still lead the debate to better understanding, at least till more relevant concepts appear.

My paper may seem to focus more on the interpretation of scholars within the positivist camp but this is because the post-positivist camp is still finding its place or is still being marginalized in the field.

\section{METHODOLOGY-KUHN AND SOCIAL SCIENCES}

\section{Natural Sciences Versus Social Sciences}

History of science chronicles the ups and downs of scientific development as a "developmentby-accumulation" (Kuhn 1970, 2). It is integral in its own time and its errors lead to the next stage of development. At any time, there is a scientific community, which strives for maximum coherence and relation to nature or reality. Thus, in any given field, experience teaches and produces the evolution of knowledge.

Anomalies change the existing scientific tradition and lead to new assumptions. This is a process of "shifts of professional commitments", known as scientific revolutions and they are "the tradition-shattering complements to the tradition-bound activity of normal science" (Kuhn 1970,6). However, the question of importance is whether scientific revolutions in natural sciences are regulated by the same rules as those in social sciences. There are some differences between natural and social sciences. The main differences, related to the structure, are that in social sciences the process is slow, changes are not so abrupt, it is sometimes difficult to see changes in the short-range period, there is complementarity through competition. All these imply debate. Debate leads to scientific progress, optimism about the development of knowledge. The result is a conceptual transformation.

Another difference is the idea of progress. In natural science Darwinism influences the interpretation of evolution as progress. However, in social sciences evolution may not have a goal or may not lead to progress. Also, there is circularity in the sense that the questions become part of a theory and thus they are subjected to the same scrutiny when applied to theories in other fields. The circularity is between the "context of discovery" and "the context of justification" (Kuhn 1970,9).

\section{Kuhn's Shift from Pessimism to Optimism or the Relativism of Applicable Knowledge}

Another characteristics of paradigms, applied to social science, is the shift from pessimism to optimism. Pessimism stems from doubts about scientific progress in the pre-paradigm period because of the multiplicity of competing schools (Kuhn 1970, 163). Optimism stems from the progress in the mature scientific community, working from a single paradigm, even if the contribution is only to an esoteric group. Optimism prevails in the notion that the reception of a common paradigm frees the scientific community from the need to constantly re-examine its first principles and the members of the 
community can concentrate upon most esoteric (or specialized) questions of analysis. Relativism stems from the fact that the problem with progress needs a more "refined" (Kuhn 1970, 170) solution. This means that changes in paradigms may not necessarily lead the scientific community closer to the truth.

\section{Kuhn's Notion of Paradigm}

In the postscript added in the second edition of his book, Kuhn clarifies the notion of paradigm. He distinguishes two kinds of paradigms or in other words elaborates and expands the original meaning. The two meanings are closely related to each other and the demarcation between them is not clear. The different interpretations of paradigm emphasize either on the one or the other meaning of paradigm and generally increase the ambiguity of the whole notion. However, Kuhn tries to make the separation between the two meanings relatively clear and his idea is that the first meaning is more narrow, while the second is broader and not confined to scientific community. The difficulty comes from the fact that the differences can be seen only when the two meanings are observed in relation to each other. This resembles the third IR debate in the fact that both sides of the debate should be treated as complementing rather that as negating each other.

The first meaning of paradigm is sociological and related to scientific community. The paradigm is described as a disciplinary matrix (Kuhn 1970,182) with four components, each of which serves a specific function. The first component consists of symbolic generalizations that provide definitions for the symbols. The second component consists of beliefs in particular models that provide the preferred analogies. The third component consists of values, usually concerning predictions. The fourth element, which is considered the most important, consists of exemplars of concrete problem solutions.

The second meaning of paradigm seems to elaborate on the fourth component of the first meaning and describes paradigms as shared examples. It relates theory to practice or how practice changes theory. Theory is a tool used for the start of analysis of a problem. Theory is a form of "tacit knowledge" (Kuhn 1970,1915), learned by doing science or applying science, rather than by acquiring rules a priori. Knowledge becomes embedded in shared exemplars or shared examples of situations. However, the interpretation of situations differs because of the different individual mental processes. Thus generalizations are relative. Misinterpretation of the same terms or concepts leads to miscommunication or partial communication. This is called incommensurability. Incommensurability prevents the creation of common basis of comparison in respect to the quality of a theory. However, the problem of incommensurability may be approached by the creation of new language. Furthermore, for real understanding to take place, there is a need for a "conversion experience" (Kuhn $1970,204)$, called gestalt switch or reprogramming of the mind. In conclusion, the second meaning is deeper and philosophical, the paradigm is a model or exemplar or an ideal that serves as a pattern' 6 .

The relation between the two meanings is provided by the community structure. The explanation of the relation starts with focus on the behaviour of the community's members. The implication is that the ablest scientists, who produce knowledge, belong to several groups simultaneously. The community structure develops in two phases. The pre-paradigm period is characterized by competition for domination between the schools. The second phase or postparadigm period is characterized by reduction of the number of schools and concentration on esoteric, puzzle-solving work. For the second phase to exist, the first must have taken place because the second phase needs the rules established in the previous phase. In the second phase, the paradigm governs a group of practitioners. The movement to the esoteric stage is called transition to maturity. Applied to science, puzzle-solving ability proves equivocal. Thus it is difficult to say who stands where. As earlier and recent theories are difficult to distinguish, there is no absolute truth but relativism. Thus mixed models are created where "do" approximates "ought". However, Kuhn is not suggesting an extreme version of relativism with no rules.

\footnotetext{
${ }^{5}$ This has been cited by Kuhn from Polanyi.

${ }^{6}$ In Criticism and the Growth of Knowledge..., Kuhn clarifies that he has used history and social-psychology as a basis for the philosophical conclusions (Kuhn 1970, 277).
} 


\section{RESULTS-DIFFERENT INTERPRETATIONS OF KUHN'S PARADIGM}

The different interpretations further complicate the actual applicability of the notion to the IR theoretical debate, because they do not specify whether their starting point is the first or the second meaning. Terence Ball's interpretation points that the concept of paradigm is an old concept that derives from the Greek paradeigma as a pattern or exemplar (Ball 1976, 155 footnote). Diana Crane interprets Kuhn more broadly and, elaborating on him, arrives at the idea of invisible college (Crane $1972,35)$ as a communication network that links groups of collaborators. This network is founded in the citations used by scholars. Scientific theories are "mental sets" (Crane 1972, 78) influencing perception. She regards scientific communities as open to the process of cross-fertilization 7 . Shared commitment for the solution of a problem creates orientation paradigms. Dietze accepts the paradigms in a similar way, as "conceptual spectacles" for the scientist (Dietze 2001, 5). However, he stresses more on Kuhn's relativism. Nickles' interpretation is broad because he accepts paradigms as puzzle-solving practices, guided by the exemplary problem solutions (Nickles 2003, 142). He finds a circular relation, which he calls a dilemma, between tradition and innovation. So, according to him Kuhn defines mature science in a circular manner and the difficulty arises because exemplars work only for a trained community of experts.

Some of the most prominent critiques of Kuhn give another meaning to the paradigm. Popper's narrow use of the word indicates a research programme, considered satisfactory by some scientists, to the point that they demand its general acceptance (Popper 1970, 558). Masterman's use indicates that paradigm has to be a concrete picture (Masterman 1970, 76), Lakatos focuses on research programmes, consisting of methodological rules (Lakatos 1970, 179) and Feyerabend focuses on puzzle-solving.

\section{The Transformed Notion of Paradigm}

Dogan and Lichbach elaborate on the broader meaning of Kuhn's paradigm ${ }^{9}$. Their ideas are more relevant to the contemporary IR debate and could be considered as a useful modification on Kuhn. Dogan elaborates on the idea that frontiers, generally in Political science, are moving and need not be defined. Heterogeneity is stimulated through exchanges between specialized sub-fields. IR is viewed as a sub-discipline of Political science ${ }^{10}$. Specialization, fragmentation and hybridization are the main features of Political science. What Dogan explains as two kinds of specialization, resembles in a way the two meanings of paradigm in Kuhn. The first kind of specialization is within a discipline and is a prerequisite for the second, which takes place at the intersection of mono-disciplinary fields (Dogan 1989, 98). The hybrid fields prove Kuhn's relativity idea because it is not clear who stands where. However, the modification is that the most fruitful work takes place not along disciplinary boundaries but between sectors. In other words the focus is on hybridization rather than interdisciplinarity. Progress proceeds at the intersection of fragmentation into special fields, and specialization by hybridization. This intersection is a recent phenomenon in Political science.

Dogan rejects the use of the word paradigm, as a grand theory in social sciences, because of the lack of theoretical consensus in any discipline. Kuhn would answer to this, that the lack of consensus and confrontation is a sign of the transition to maturation and part of the pre-paradigm period. Dogan argues that there are no paradigms as long as each discipline is fragmented and as long as theories do not reflect the changes in reality. However, Dogan acknowledges that there is "some loose sense of Kuhn's paradigm that fits in social sciences" (Dogan 1989, 106) and this is the existence of a cumulative process of lessons learned. In this sense, grand theories, as the middlerange rational choice, have to be replaced by interdisciplinary methods.

Lichbach would agree with Dogan on the issue that grand or hegemonic theories should be abandoned. He accepts the idea of methodological synthesis of positivism and interpretivism (Lichbach 2003 115). According to him the three research communities or traditions now, are

\footnotetext{
${ }^{7}$ Kuhn is an example of this process because he starts his career as a physicist and then focuses on the history of science.

${ }^{8}$ For Popper, Masterman, Lakatos and Feyerabend I refer to Criticism and the Growth of Knowledge

${ }^{9}$ A. Chalmers also views Kuhn's paradigms broadly, as structures or frameworks.

${ }^{10}$ According to the appendix: (Dogan 1998, 36) Keohane, Waltz, Holsti and Krasner are the most frequently referenced authors in IR.
} 
rationalists, culturalists and structuralists. Each of them specializes but generally the research programmes thicken over time. The synthesis would be a product of a post-paradigmatic world with no debates. Thus the modification of Lichbach on Kuhn is that the word paradigm exists only when there are debates between the traditions. However, he also agrees that there is a sense of paradigm as a framework, as creating a problem-centered, complementary synergy between the traditions, with respect to a single case. Thus the paradigm creates one understanding of a case and prevents the cacophony of voices. Synthesis is "tripartite coalition" (Lichbach 2003,131) between modest traditions, acknowledging the relativism of knowledge and facilitating debates. Progress happens when the right tools are applied to the given situation. Thus, the Kuhnian exemplars are used to solve problems (Lichbach 2003, 180). Models become mediators between theories and data. This is close to Kuhn's paradigm as a collection of models applied to specific problems. ${ }^{11}$

Nested models synthesize different paradigms. Modelling is an endless trial and error process. Theory criteria should stand between positivism and relativism (Lichbach 2003, 199). The criteria are neither positivistic, nor idealistic but pragmatic because they account for reality ${ }^{12}$.

\section{KUHN AND THE THIRD IR DEBATE}

\section{General Overview}

The first debate happens during the 1920s-30s between idealism and realism. The second debate in the 1950s-60s is about history versus science and the third debate, starting around the 1980 s is generally considered to be between positivism and post-positivism ${ }^{13}$. The IR scholars stand differently on the positivism-relativism scale and their actual position is debatable. The debate is provoked by the positivism's or behaviorism's failure to reach the absolute objective truth without selfcriticism. Many authors writing about the debate refer to Lapid who presents the debate as positivism versus post-positivism or reflexivity. This pessimism-optimism shift becomes a feature of the third debate and post-positivism.

At the same time the debate is also inter-paradigmatic because paradigms evaluate each other. This kind of reflexiveness creates a different from the Kuhnian relativism, because in this case the lack of consensus may lead to progress, a sign of maturation. However, pluralism should also be reflective in order to result in communication rather than cacophony of voices.

\section{The Pessimists}

The more narrow interpretation of the debate is illustrated by Waltz's focus on positivism. Waltz is pessimistic because of his realistic assumptions. According to him greater interdependence means more conflict. Thus he sees the debate as a battle of paradigms where problem-solving is discouraged because the sides of the debate talk different languages (Waltz 1998, 372). In fact he admits that he has written the three images ${ }^{14}$ because he wanted to facilitate this communication or create the structure for communication across the levels of analysis.

However, his biography proves that diversity in the field exists and that IR imports from other disciplines. He has majored in maths and economic and then turned to political philosophy. Then it is not surprising that he remains influenced by natural sciences. He argues that theory is an instrument (Waltz 1998, 381) and that history, interpretation, philosophy are not a theory but rather an application of it, embedded in society and politics. In other words structural realism is seen as the only theory and the rest as its application. According to him (Waltz 1990), neorealism is the paradigm in IR and this paradigm uses the logic of causality and behaviorism, which are typical for the second IR debate.

\footnotetext{
11 Lichbach uses the terms research communities, traditions, languages, schools, approaches, paradigms, programs, and frameworks interchangeably.

${ }_{12}$ This very much resembles what Wendt calls scientific realism (appears later in my essay).

${ }^{13}$ However, as Lapid mentions in the footnote on page 238 of his article, there are variations in the meaning of the debate. For example Keohane restricts its scope as a debate between neorealism and its challengers, while Holsti and Biersteker focus more broadly on the debate within the multi-paradigmatic IR discipline. Still others (mainly constructivists) consider its main feature the knowledge versus power dimension or the opposition of vested interests.

14 "Man, the State, and War", Columbia Univ. Press, 1959, or the individual, state and system level.
} 
Skocpol considers interrelations but in a sociological perspective. Sociology is relatively free of metatheory or the desire for classification (Skocpol 1987, 10). Instead the focus is on problemsolution and comparative history. Skocpol argues that metatheories run the risk of creating artificial ideal, typical categorizations that obscure the genuine research tendencies. She relates social and political processes and is pessimistic about any grand-theories. In Kuhnian language, may be, she proves the fact that IR still import from other disciplines and sociology is not a discipline that encourages any fixed paradigms.

\section{The Optimists}

Contrary to Waltz, Alker and Biersteker are optimistic and see the debate and knowledge cumulation from an archeological perspective. Their idea is that positivism is still alive mainly in the "parochial and myopic" (Alker, Biersteker 1984, 121) American approach to the discipline. They use a comparative examination of reading-lists in universities to prove this thesis. They believe in synthetic dialectics ${ }^{15}$ and the study of historical contexts. Approaches, however, can reach synthesis only if debates involve more tact as opposed to being hegemonic. Thus IR is seen as a global " interdiscipline"16 (Alker, Biersteker 1984, 122), composed of many approaches at any time and setting. The synthesis is possible under the form of dialectical triad (p.124), which consists of traditional approaches (realism and idealism), dialectical approaches (nationalism and proletarian internationalism) and behavioural approaches (neo-realism and liberal internationalism). Each approach produces paradigm-like research programs and interdisciplinary debates between opposing approaches can generate knowledge. The ambition is a perfect pluralism of traditions. Their suggestion for "international savoir faire" (Alker, Biersteker 1984, 137) resembles Lickbach's idea for moderate scientific approaches. The conclusion is that humility and openness in the development of a theory facilitate adaptation.

Holsti is optimistic and views the debate more broadly. In response to Lapid's essay, Holsti's main concern is about the lack of standards in theoretical pluralism. Thus the main question for scientists becomes how to move from self-reflection, as mirror-image, to self-reflexiveness or selfcriticism as a standard for the debate. Theoretical pluralism expresses the "diverging intellectual roots" (Holsti 1989, 256) of the discipline. However, any going to extremes, as either establishment of a hegemonic theory or abandonment of any basis, should be avoided.

According to him, the Kuhnian ideas "fit poorly" (Holsti 1989, 255) in the current discipline transition ${ }^{17}$. Holsti explains intellectual progress as a slow-moving process, where the old and new explanatory systems are interconnected. Thus the focus is not on the replacement of paradigms. This is the kind of modification on Kuhn, also mentioned by Lichbach, seeing paradigms as patterns. The reason is that the anomalies between reality and theory in social sciences are not so harsh as in natural sciences. Social sciences are not replaced but modified because some essential truths of the explanatory system remain. He suggests that theoretical innovation cannot be separated from data and may be this data represents for him the essential truth. ${ }^{18}$

A consensus is a prerequisite for the developing of a theory. Up to the third debate the consensus has been provided by the classical IR tradition. Now the challenge to this tradition is more normative rather than scientific. Thus paradigms reflect normative positions and value preference and this makes the debate more difficult (Holsti 1985, 132). Currently, Holsti thinks that the States system paradigm is challenged by the other two paradigms: the Global society paradigm (known as English school) and the Neo-Marxist Paradigm (mostly Gramscian school) ${ }^{19}$.

Wendt is generally an optimist and is considered as the middle -ground by positivists. His theory is thick because he combines ideas, structure, agency and culture. His ontology is idealistic

\footnotetext{
15 This notion of dialectics resembles the Hegelian unity of opposites, or the critical method of synthesis produced by thesis and antithesis.

${ }^{16}$ As the authors admit, this term is borrowed from Dougherty and Pfalzgraff, 1981.

17 However, in a footnote on page 14 in The Dividing Discipline, Holsti admits that Kuhn's paradigms have a broad meaning, being not only rooted in "rationally analyzable differences, but in trans-rational perceptions or gestalts" as well.

${ }^{18} \mathrm{He}$ enumerates several sources for theoretical innovation: events, facts, other theories, values and meta-theoretical debates.

19 The explanation in brackets is mine, not Holsti's.
} 
and that is where the main difference with positivism comes. According to him, the contemporary IR discourse is influenced by two structural theories, neo-realism and world-system theory, which both he criticizes from a sociologist perspective (Wendt 1987, 335). As a result he suggests the need for a scientific realism ${ }^{20}$ as the "new orthodoxy" in the philosophy of natural science, usually associated with the Minnesota Center for the Philosophy of Science (Wendt 1987, 336,footnote 4). In Kuhn's language may be this scientific realism forms for Wendt the loose paradigm for the future debate.

Wendt sees the debate as between empiricists (mainly hard-core realists) and scientific realists. His main critique of empiricists (neo-realists) is that the system should not be treated as given and unproblematic. In other words he argues that empiricists subordinate ontology to epistemology and what exists becomes a function of what can be known experimentally. By contrast, scientific realists agree with abductive ${ }^{21}$ inference or retroduction, or the idea of adapting the assumptions to real world changes. Scientific realism is necessary for making scientific practices rationally intelligible and also for maturation of science. Wendt further suggests the need for a structuration theory as an analytical tool for elaboration on structure because social structures differ from natural structures (Wendt 1987, 355). This new tool implies the mutual construction of agents and structure.

Ferguson and Little are optimistic and consider paradigmatism as formulating and applying valid evidence procedures. Diversity, especially after the end of the Cold war, is not a sign of fragmentation in the field but rather increases the strength of the field. This diversity, or adoption of eclectic vision encourages dialogue and self-reflection. From Kuhn's perspective IR are operating in a pre-paradigmatic phase because of the theoretical conflicts ${ }^{22}$. The problem is in the different interpretation of paradigms. While positivists tend to broaden the theoretical base and assume that paradigms can co-exist and compete, post-positivists assume that paradigms are the main way for pointing at differences and "inherently incommensurable ways of looking at the world". After all, there is optimism because diversity means diversification, common ground as thickening of the approaches, and overlaps between the approaches that prevent the possibility of a zero-sum game as a final outcome.

Rosenau is also optimistic in his view of paradigm proliferation. He argues that change is pervasive and coexists with continuity. For change to be adequately represented in theories, there is a need for new models of cooperation. In this sense he appreciates the contribution of both Keohane and Oye as a modification of neo-realism ${ }^{23}$. According to Rosenau "grandiose" theories have to be evaluated for their sensitivity to change (Rosenau 1986, 856). He suggests that the focus should be not on the micro and macro levels of analysis but rather on micro and macro levels of aggregation. The latter focuses on the world itself, not on the analyst. Thus he includes a normative dimension of the analysis. The criteria, or exemplars in Kuhn's language, for a grandiose theory are the relations or interactions of micro and macro variables (Rosenau 1986, 852). These relations cannot be taken for granted and that is why the research agenda is stimulated by habit-driven actor approach. The idea is that habit is flexible and adapts to changes in different situations.

\section{The Mixture of the Middle Ground}

Krasner is both optimistic and pessimistic. He is pessimistic because he focuses on Kuhn's incommensurability thesis and thus the lack of communication. Theory incommensurability comes from the relative meanings of terms, the different terms used by the competing approaches and the different dependent variables used by the theories (Krasner 1985, 138). The difficulty stems also from the lack of clear rules for the operationalization of variables in social science ${ }^{24}$.

\footnotetext{
${ }^{20}$ Scientific realism is not related to IR realism and neorealism.

${ }^{21}$ Abduction refers to cognition and intuitive notions of causality. The term is coined by Charles Pierce. For him the introduction of unifying conceptions is an important part of abduction. Abduction does not occur in the context of a fixed language, because the formation of new hypotheses goes hand in hand with the development of new theoretical terms as " atom" or "AIDS". Abductive reasoning is, according to Pierce, the first stage of scientific inquiries and of any interpretive process. Abduction is the process of adopting an explanatory hypothesis and covers two operations: the selection and the formation of plausible hypotheses.

${ }_{22}$ The electronic article does not have page numbering.

${ }^{23}$ Rosenau reviews Keohane's After Hegemony and Oye's Cooperation under Anarchy (Rosenau 1986).

${ }^{24}$ Krasner disagrees with Bueno de Mesquita's quantitative research and over-reliance on large number of comparable cases (Krasner 1985: 140).
} 
However, he is slightly optimistic because he thinks that objective criteria or basis of communication can be developed by "inter-subjective agreement on the meaning of variables" (Krasner 1985, 139) achieved by a science with a humble image.

Vasquez is a good example of a shifting of opinion happening in the mainstream. He moves from realism to constructivism and is mostly pessimistic. He argues that the realist paradigm is the dominant one and its challengers degenerate the paradigm's research program. Vasquez thinks that the IR field needs more rigor in the inter-paradigm debate. Thus he sides more with Lakatos' idea of hard core. However, he uses Kuhn to explain that, "paradigms do not provide answers but the promise of answers" (Vasquez 1997, 899). Thus the adequacy of the theories generated by a paradigm may be judged only indirectly. In Kuhn's language, according to Vasquez, there is a consensus in the English-speaking world that the realist paradigm has dominated the IR. Morgenthau's Politics among Nations is considered as an exemplar of the paradigm. Consequently security, peace and war still remain the main themes.

Gradually there has been a shift in Vasquez's opinion because he is more optimistic about the debate between realism and constructivism. Basically he thinks that the mainstream can be "saved" by the constructivist paradigm or that constructivism" has emerged as an alternative intellectual pillar of mainstream international relations theory" (Vasquez 2004, 1). He moves to the idea that facts are not just there but "come from us "or that there are "multiple worlds" (Vasquez 2004: 3). In Kuhnian language, constructivism and positivism are seen as two approaches that constitute the same scientific community and thus communication between them should be maintained. In other words they form "a loose community of inquiry" (Vasquez 2004, 2). The author wants to achieve overlapping between the approaches but he does not consider any post-positivist approaches. This questions the idea of diversity pluralism or the pluralism between his "loose community" and other communities. However, in this way he provides some kind of a loose framework for knowledge.The problem, however, comes from the fact that when talking about realism Vasquez understands the hard core, while Wendt has something else in mind 25 .

One of the discussions, related to the IR debate, proves the shift from pessimism to optimism as a tendency (The Forum 2003). The forum is considered by Lapid (The Forum 2003, 129) as a dialogue about the future dialogue or as a meta-theoretical prelude. The opinions of the participants vary. Hellmann is sceptical because he argues that there is much monologue and arguing in the discipline. He suggests that the formula is debate rather than dialogue. Although this questions the ideal view of scientific community, still dialogue and synthesis serve as loose guides for the future in the Kuhnian sense. Synthesis remains "an endless journey" (The Forum-Hellmann 2003, 149) or "engaged pluralism" in Lapids' words. Paradigmatism, if rigorously defined, is a hindrance. Thus dialogues between individual scholars rather than between paradigms are encouraged.

Friedrich Kratochwi agrees with Hellmann on the issue of the monologue of science but is more optimistic about the constructive role of procedural standards of fairness in the debate. The standards for him (or loose paradigms) are represented by "quasi-judicial procedures" (The Forum $2003,125)$ that can judge the weight of controversial evidence. Ethical or professional standards prevent the kind of relativistic pluralism of "anything goes". This is similar to a legal process or problem-solving approach.

Lapid is optimistic about the role of the dialogue as a remedy to knowledge problems. He considers the current stage of the dialogue as a preparatory one, done at a disciplinary level. In other words, this first stage is an exercise for leading a reflexive dialogue and the main task is the participants to define the meanings of concepts or more precisely-give nuanced meanings of concepts. The actual inter-paradigm debate is at the second stage that will be "theory-paradigm level"

\footnotetext{
${ }^{25}$ This may be proves that terms have different meanings for different approaches and the idea of incommensurability. A good example on the difference of emphasis placed upon the concepts (by realists and constructivists) is the theory of world risk society, explained by Ulrich Beck. Realists focus on the adjectives world and risk and consequently the risk is accepted as a part of a global model, without self-reflection. Constructivists, on the other hand, focus on the noun society and consequently are more open to the idea of trans-nationality. Ulrich Beck also coins the term "reflexive modernity" as a theory for society's self-criticism.
} 
(The Forum 2003, 129). At the second stage the dialogue will need a mediator or many mediators in the form of middle-ground ideas. This is Lapid's loose sense of a paradigm.

Moravcsik's loose paradigm is more close to positivism in a sense that he believes in empirical testing. He suggests that the overreaching assumptions embedded in a given model have to be minimally coherent (The Forum 2003, 132). What is more, theoretical synthesis has to be put to empirical testing just like any theory. However, this synthesis should help the understanding of concrete events as opposed to positivists' strive for universality.

Neumann sides more with post-positivism and starts with questioning the mere assumption that dialogue leads to synthesis in a causal way (The Forum 2003, 137). In other words dialogue may not have a purpose. Participants in the dialogue may not use the proper language or over-rely on reordering old language signs instead of creating new ones. Actually, they disregard the idea that different contexts call for different stylistic modes for enhancing cooperation. As a result monologue and war are not unfortunate scenarios for the future ${ }^{26}$.

Like Neumann, Steve Smith also suggests that dialogue differs from synthesis. However, without a dialogue, ideas "fossilize in a extreme kind of Kuhnian normal science" (The Forum 2003, 141). Smith considers the great debates as times of paradigm crisis in Kuhnian normal science. His opinion is that Kuhn is very imprecise over the meaning of paradigm and this further complicates the debate (Ken Booth and Steve Smith 1995, 15).

For Harvey and Cobb (The Forum 2003, 144), synthesis is nuanced and hard to be achieved because the methodological division is multi-layered. The middle ground, in this sense, further increases the division.

\section{On Eclecticism}

The forum proves that political science in general and IR in particular is eclectic. This is also the conclusion of Katzenstein, Keohane and Krasner (Katzenstein, Keohane and Krasner 1999,6) when they consider the post-cold war opening of the discipline. Although this opening challenges realism, there is also a close interaction between comparative and international relations scholars and a degree of complementarity between rationalism and constructivism. Thus, theory follows practice and the main task of a theory is to solve puzzles. An example of this line of thinking is Keohane's modification on realism by liberal institutionalism ${ }^{27}$. As he suggests, if theories are not connected with experience they may become dogmas.

\section{CONCLUSIONS}

The paradox in the debate is that pessimism and optimism reinforce each other. The pragmatic tendency is towards eclecticism of the approaches. Elements are interrelated and the border between positivism and relativism is moving. Situations change, so do combinations of approaches to explain them. There are no universal theories that explain everything. Rather scientists better talk about approaches that form relatively stable syntheses. To encompass the complex reality, combinations should be different because different combinations present the reality from different perspectives. In this respect, one of Kuhn's contributions is that he starts the doubt in positivism, liberates knowledge, and science becomes more problem-driven that theory-driven. However, he also demands for exemplars that regulate the process. Thus in Kuhn's language positivism and relativism cannot be separated. The same argument applies for pessimism and optimism.

Pessimists emphasize on the clash of approaches and lack of communication. Those who are a little more optimistic think that IR needs preparation before the essential debate. Usually this means that some accept the third debate as a preparation for the fourth or main debate between positivism and post-positivism. The optimists believe in the possibility of a synthesis between approaches, a dialogue, cross-fertilization.

\footnotetext{
${ }^{26}$ The author uses Mikhail Bakhtin's explanation of dialogue as an ethical imperative. Bakhtin is a Russian linguist and literary critic whose writings influence structuralism, post-structuralism and social theory in the $20^{\text {th }}$ century.

${ }^{27}$ For more on Keohane's opinion see Goodin and Klingemann..., ch.19.
} 
Grand narratives or paradigms are unable to explain all situations because the world is becoming more complex and there is agreement (according to Dogan) on that issue within the IR scientific community. Thus the movement is towards synthesis in the form of dialogue, towards relativism as different approaches or models valid for different situations. The main task in IR is how to move from the stage of pluralism to meaningful pluralism. The former is no more than a reflection of the statement "let's agree to disagree" and the latter shows the real maturation signs (may be second stage of maturation) - a movement to "let's agree how to reach an agreement that will solve real problems" and finally may be realize that disagreements or debates should not be the focus of a theory or that debates should not create divisions but unite scientific resources in search of the solution to problems. After all, although there should not be a single grand paradigm, a loose paradigm as a framework is better than no framework at all.

\section{REFERENCES}

Alker, Hayward. Thomas Biersteker. 1984. "The Dialectics of World Order: Notes for a Future Archeologist of International Savoir Faire", International Studies Quarterly, Vol. 28, No 2, 121-142.

Ball, Terence. 1976. "From Paradigms to Research Programs: Toward a Post-Kuhnian Political Science“, American Journal of Political Science, Vol.20, 151-177.

Booth, Ken and Steve Smith, ed. 1995. International Relations Theory Today, Polity Press.

Chalmers, A. F. 1999. What is This Thing Called Science?, Open Univ. Press, UK, ch.8-p.104-129

Crane, Diana. 1972. Invisible Colleges, Diffusion of Knowledge in Scientific Communities, University of Chicago.

Dogan, Mattei. 1998. "Political Science and the Other Social Sciences" in Robert Goodin and HansDieter Klingemann, eds. A New Handbook of Political Science, ch.3.

Ferguson, Yale and Richard Little. 2004. "From International Politics to Global politics: An Evolving Field", Standing Group on International Relations, prepared for presentation at the fifth Pan European International Relations Conference, Netherlands, The Hague, www.sgir.org

Geller, Daniel and John Vasquez. 2004. "The Construction and Cumulation of Knowledge in International Relations: Introduction", International Studies Review, 6, 1-6.

Halliday, Fred and Justin Rosenberg. 1998. Interview with Ken Waltz, Review of International Studies, 24, 371-386.

Hellman, Gunter. 2003. ed. "The Forum: Are Dialogue and Synthesis Possible in International Relations?,"International Studies Review, 123-153.

Holsti. K. 1989. "Mirror, Mirror on the Wall, Which Are the Fairest Theories of All?," International Studies Quarterly, Vol. 33, No. 3, 255-261.

Holsti, K. 1985. The Dividing Discipline, Hegemony and Diversity in International Theory, "Allen and Unwin" Inc.

Katzenstein, Peter, Robert Keohane, and Stephen Krasner, ed. 1999. Exploration and Contestation in the Study of World Politics, The MIT Press, ch.1.

Krasner. Stephen. 1985. "Toward Understanding in International Relations," International Studies Quarterly, Vol .29, No. 2, 137- 144.

Kuhn, Thomas. 1970. The Structure of Scientific Revolutions, $2^{\text {nd }}$ ed., Univ. of Chicago.

Kuhn, Thomas. 1970. "Reflections on My Critics", in Criticism and the Growth of Knowledge, ed. by Imre Lakatos and Alan Musgrave, Cambridge Univ. Press, 231-277. 
Lapid. Yosef. 1989. "The Third Debate: On the Prospects of International Theory in a Post-Positivist Era,"International Studies Quarterly, Vol.33, No3, 235-254.

Lickbach, Mark. 2003. Is Rational Choice All of Social Science?, Part IV, ch.7, The University of Michigan Press, USA.

Nickles, Thomas. 2003. "Normal Science: From Logic to Case - Based and Model - Based Reasoning", 142-177, in Thomas Kuhn, ed. by Thomas Nickles, Cambridge Univ. Press.

Rosenau, James. 1986. "Before Cooperation: Hegemons, Regimes, and Habit-driven Actors in World Politics, "International Organization 40", 4, 849-894.

Skocpol, Theda. 1987. "The Dead End of Metatheory", Contemporary Sociology, Vol .16, No. 1, 1-6.

Vasquez, John. 1997. "The Realist Paradigm and Degenerative versus Progressive Research Programs: An Appraisal of Neotraditional Research on Waltz's Balancing Proposition", The American Political Science Review, Vol. 91, No. 4, 899- 912.

Von Dietze, Erich. 2001. Paradigms Explained, Rethinking Thomas Kuhn's Philosophy of Science, Prager Publisher.

Waltz. K. 1990. "Realist Thought and Neorealist Theory“, Journal of International Affairs, Vol. 44.

Wendt, Alexander. 1987. "The Agent-Structure Problem in International Relations Theory", International Organization, Vol. 41, No.3, 335-370. 